\title{
RAPID PROTOTYPING IN 2K17-AN OVERVIEW
}

\author{
DIVYA SADHANA. A \& ANBARASAN. R \\ Department of Mechanical Engineering, Vel Tech Rangarajan Dr. Sagunthala R\&D Institute of \\ Science and Technology, Chennai, Tamil Nadu, India
}

\begin{abstract}
Recently additive manufacturing is proudly called as "the third industrial revolution". For more than two decades research was going on in the development of Additive Manufacturing (AM) technology. Additive manufacturing is the process of building parts by adding materials one layer above another layer. This paper overviews the highest achievements of Additive Manufacturing (AM) technology in various fields for various applications, such as biomedical, automotive, aerospace, etc. in the year $2 k 17$.

KEYWORDS: Additive Manufacturing, Rapid Prototyping \& Industrial Revolution
\end{abstract}

Received: Jun 17, 2018; Accepted: Jul 13, 2018; Published: Aug 01, 2018; Paper Id: IJMPERDAUG201889

\section{INTRODUCTION}

Rapid prototyping Technology first started to develop in early 1990s to raise in its sophistication and for its applications. Additive Manufacturing (AM) is the emerging technology in which parts are build-up with layer-by layer in additive manner. Nowadays investments for research and development in additive manufacturing have grown rapidly in the government and private sectors all over the world. By 2020 the market for additive manufacturing products and services was planned to grow to over $\$ 5$ billion (Wohlers, 2011) [1]. Additive Manufacturing machines can be found in industries, homes, institutions and government. With rapid prototyping, students and scientists can rapidly build and analyse models. Doctors can build a model of injured tissues or damaged bones. Through rapid prototyping artists can discover their creativity which will be easy for market researchers. At present, the technologies of rapid prototyping are not just used for creating models, with the advantages in plastic materials, it has been possible to create finished products, and of course at the beginning they were developed to expand the situations tested in the prototyping process [2].

\section{OVERVIEW OF ADDITIVE MANUACTURING}

The 3D printing in Zero-G Technology demonstrates that a 3D printer works normally in space. At International Space Stations (ISS), Zero-G Technology serves as a proof-of-concept test for the properties of melt deposition modelling in microgravity environment. It was the first additive manufacturing demonstration in space. The material used for melt deposition modelling in space is Acrylonitrile Butadiene Styrene (ABS). On comparison with the experiment made on earth with those made in microgravity. The result states that the 3D printing works in microgravity could improve 3D printing methods for industry [3]. Marshall Space Flight Made in Space 3D printer inside the Microgravity Science Glovebox (MSG) is shown in the Figure 1. 


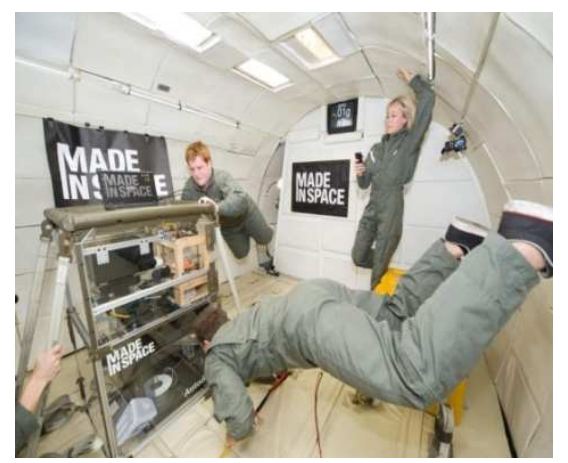

(Source: NASA)

Figure 1: Marshall Space Flight Made in Space 3D Printer inside the Microgravity Science Glovebox (MSG)

Due to lack of availability of donors for face transplantation, 3D printed models and surgical guide lines help in successful face transplantation. There was a life changing moment for a 32-year-old Andy Sandness by facial reconstruction surgery. Face transplantation is a combination of procedures which includes jaw surgery, facial nerve surgery, eyelid surgery, etc. This transplant requires full reconstruction of facial and almost all the tissues below his eyes. It has been ensured that after the operation, Sandness was able to move his face in a naturalistic scanner. 3D printed parts required for facial reconstruction are shown in the Figure 2.

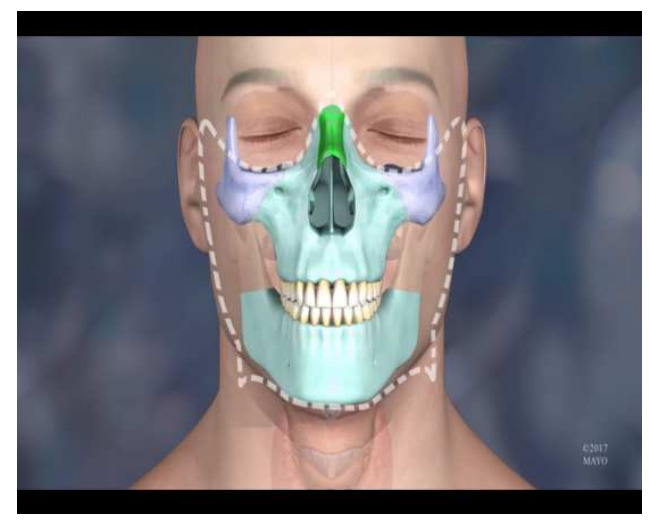

(Source: The Mayo Clinic)

Figure 2: 3D Printed Parts Required For Facial Reconstruction

By using 3D printing technology Ferrari developed pistons for its new engine. Magneti Marelli, Italian engineering company together with Ferrari created a new stronger piston made with steel alloy with complex geometries for topology optimization. The existing piston is made up of aluminium material, it was failed when subjected to high temperature and stress. When compared with aluminium, steel alloy provides greater strength and heat resistance.

The first 3D Printed aircraft component by U.S Navy used inside a T-44 Pegasus airplane, a maiden voyage of its Crew Dragon spacecraft is set by SpaceX is shown in the Figure 3. 


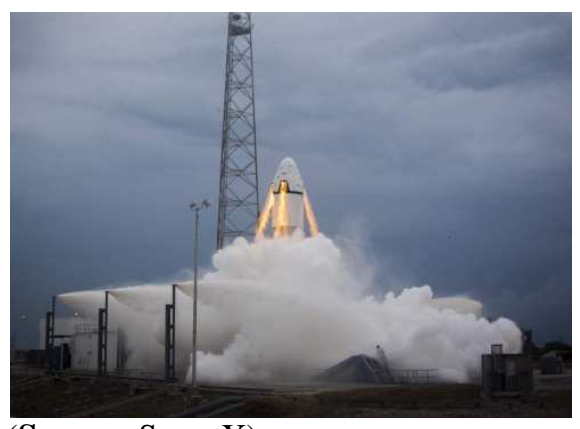

(Source: SpaceX)

Figure 3: Crew Dragon Spacecraft

MIT Researchers created a 3D Printed robotic hydrogel device. This device is capable of releasing and catching live fish. The function of this device is similar to claw crane. When water is pumped into the robots $3 \mathrm{D}$ printed arms expands rapidly, stretch out, and then it contract at a force of several Newtons per second.

For the RL10 rocket engine, Aerojet Rocketdyne leading company has successfully tested an additively manufactured thrust chamber assembly (Figure 4) which was built with copper alloy by using Selective Laser Melting (SLM) technology. It was referred as the largest 3D printed copper-alloy thrust chamber and which has been tested successfully. This 3D printed copper thrust chamber replaces a previously usedcomplex stainless steel tube. By using 3D printing technology it reduced the number of parts in the thrust chamber by $90 \%$ in just two components.

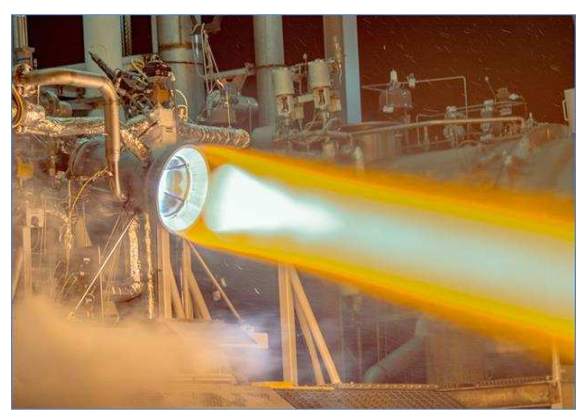

(Source: Aerojet Rocketdyne)

\section{Figure 4: Copper Thrust Chamber of RL10 Rocket Engine}

ETH Zurich Researchers created the world's first artificial heart which is made up of silicone. It has a silicone mono block with complex inner structure and weighs around 390 grams with a volume of $679 \mathrm{~cm}^{3}$. The life span lasts less than an hour, which is, it can last about 3000 beats. Boeing 787 Dreamliner was the first commercial airplane to fly with certified additive-manufactured titanium parts in structural applications.

US Navy and Oak Ridge National Laboratory (ORNL) combined and 3D printed a 30 feet long submarine hull, which is shown in the Figure 5. This submarine hull was made up of carbon fiber composite printed through FDM with Big Area Additive Manufacturing (BAAM) Technology. 


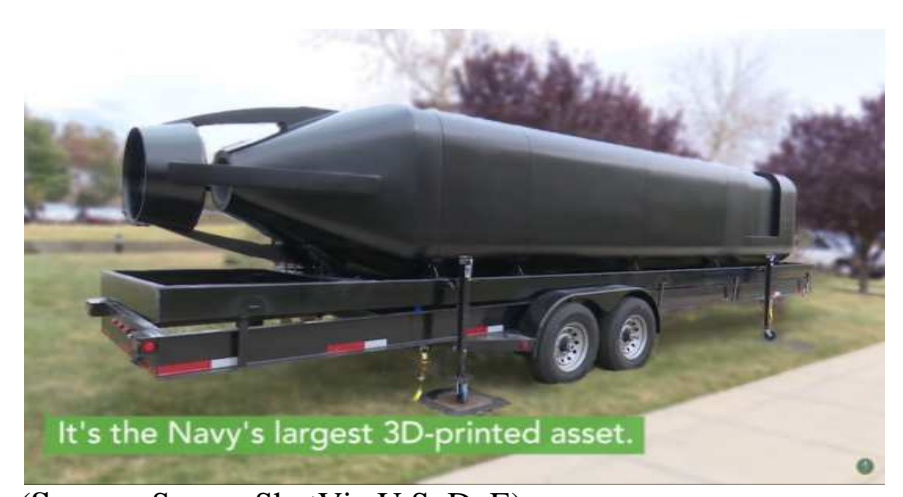

(Source: Screen ShotVia U.S. DoE)

Figure 5: The U.S Navy's Largest 3D Printed Submarine Hull

3D printing technology moves one step forward in medical applications. It was first in the world to save the leg of an Australian patient Reuben Lichter. In an operation he received a 3D printed tibia bone to restore disintegrated bone in his right leg. This 3D printed tibia acts as a scaffold to merge existing cells from the body, and eventually it allows the patient to walk again.

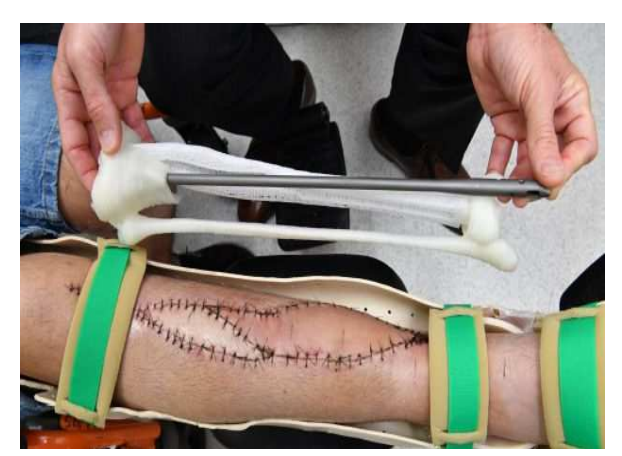

(Source: Via The Sydney Morning Herald)

Figure 6: The 3D Printed Model of Tibia Bone

3D printing is used in a combined bone graft and 3D printed implant surgery at NHS Morriston Hospital in Swansea. It has been the world's first 3D printed implant surgery to receive a jaw reconstruction surgery, combining traditional bone grafts and 3D printed Titanium implants. This implant will fix the fibula bone where implants could be set and maintained its aesthetic shape of the jaw line. Surgeons traditionally used a length of fibula taken from the leg to replace sections of jaw which had to be removed because of cancer. To keep the bone alive, the fibula section includes its own blood supply, which has to be connected to the blood vessels in the neck.

NASA had successfully tested bi-metallic 3D printed rocket igniter which completes 30 firing tests at the Marshall Space Flight Center. The Prototype Igniter is bi-metallic where the combination of copper alloy and Inconel. It has been joined together by using automated blown powder laser deposition is a unique hybrid 3D printing. The Size of the igniter is 10 inches tall and 7 inches wider diameter.

Russian construction company, AMT-SPETSAVIA completed the first 3D printed as house permanent habitation. The components required for the main box of the house were made by S-6044 printer by using M-300, a concrete and sand mixture, and later it was assembled manually. The layers produced by the $3 \mathrm{D}$ printing process are between 30 and $50 \mathrm{~mm}$ in width and the z-axis $10 \mathrm{~mm}$ in height. The S-6044 large format "portal printer" is supported by gantries, which is able to 3D print the concrete mixture anywhere within the area of $3.5 \times 3.6 \times 1$ square meters. 
Prefabrication of the elements of the house is shown in the Figure 7.

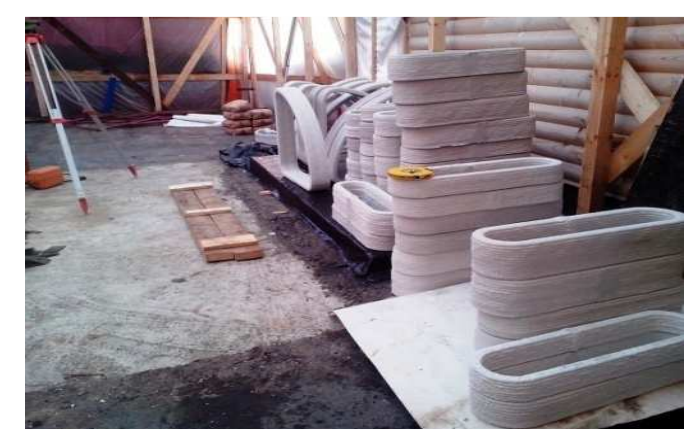

(Source: SPETSAVIA)

Figure 7: Prefabrication of the Elements of the House

First time in the history, 3D printing has been used to duplicate historical artifacts, at a high risk from weathering, Yungang Grottoes Research Institute, Qingdao Publishing Group and Zhejiang University printed the replicas of the Yungang caves by 3D Printing. At the Chinese city of Qingdao, these three ancient Buddhist statues have been put on display to the public. Figure 8 shows the replicas in the city of Qingdao.

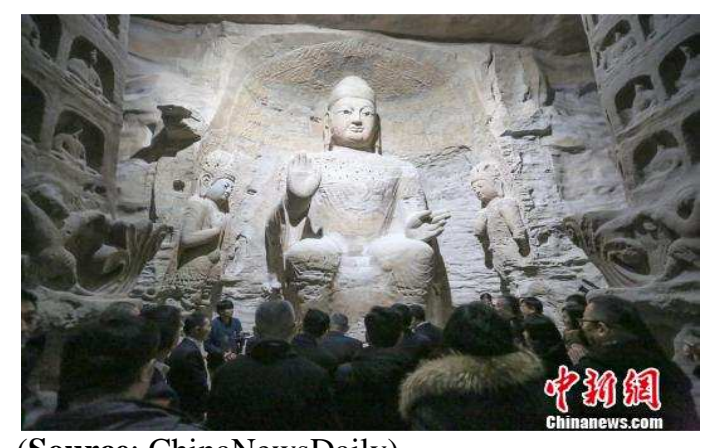

(Source: ChinaNewsDaily)

Figure 8: The Replicas in Qingdao

Researchers from the University of Kansas collected the scanned objects from the museums and private collections across the world. The diagram of the preserve amphibians has been scanned and printed with 3D effect. By 3D artifact scanning, the scan of the world projects has been achieved 10,000 objects since its beginning from 2014.

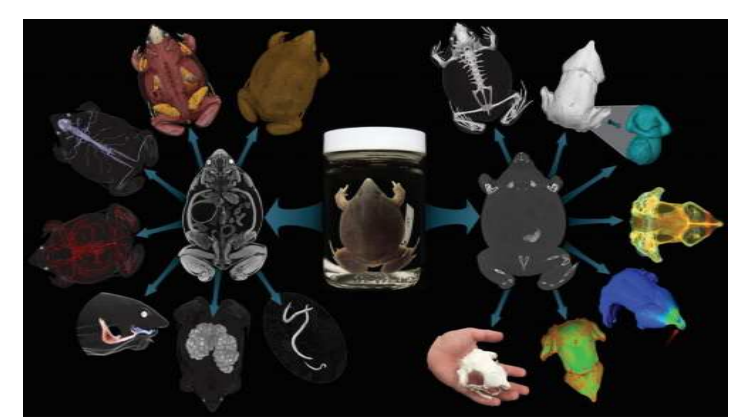

(Source: University of Kansas)

Figure 9: A Diagram of Preserved Amphibian

Besides 3D printing in engineering, medical and bio-printing applications, it moves one step ahead in making of 3D printed sensors. Students from the University of Washington (UW) used 3D Printed sensors, for making the conductive strips made of copper-containing plastic filament, which create smarter plastic objects and helps in wireless 
communication which neglect the usage of batteries.

\section{CONCLUSIONS}

This paper discusses about Additive Manufacturing technologies, which are helpful in today's trending technologies and also explains its usefulness in the current economic status.

Growth of these technologies has progressed according to applications, materials and how the designers have applied their creativity to such a unique manufacturing tools.

In future it was expected there should be more research work in biomedical engineering. Further it shows, through recent developments in AM by giving promising future to the entrepreneurs.

\section{REFERENCES}

1. Wohlers, T.T, 2011: "Additive Manufacturing and 3D Printing State of the Industry Annual Worldwide Progress Report", Wohlers Associates, Inc., Fort Collins, CO.

2. K. Cooper, 2001" Rapid Prototyping Technology".

3. https://www.nasa.gov/mission_pages/station/research/experiments/1115.html

4. Hollister,S. J. 2005 “Porous scaffold design for tissue engineering," Nature Materials, vol. 4, no. 7, pp. 518-524.

5. M. A. Stoodley, J. R. Abbott, and D. A. Simpson,, 1996 "Titanium cranioplasty using 3-D computer modelling of skull defects," Journal of Clinical Neuroscience, vol. 3, no. 2, pp. 149-155.

6. B. Christensen, 2009 “New device prints human tissue,", http://www.livescience.com/5977-device-prints-human-tissue. html.

7. T. Qian and Y. Wang, 2010 "Micro/nano-fabrication technologies for cell biology," Medical and Biological Engineering andComputing, vol. 48, no. 10, pp. 1023-1032.

8. Specifications, C. U. L. T. R. Prototyping A Tow Line Conveyor With Bluetooth Controller Using Line Tracing Robot Specifications.

9. S. J. Song, J. Choi, Y. D. Park, 2011 "Sodium alginate hydrogel based bioprinting using a novel multinozzlebioprinting system," Artificial Organs, vol. 35, no. 11, pp. 1132-1136.

10. V.Mironov, N. Reis, and B. Derby, 2006 “Bioprinting: a beginning," Tissue Engineering, vol. 12, no. 4, pp. 631-634s.

11. B. van der Schueren, J.P. Kruth, 1995,"Powder deposition in selective metal powder sintering", Rapid Prototyp. J. 1 (3) $23 e 31$.

12. C. Emmelmann, J. Kranz, D. Herzog, E. Wycisk, Laser additive manufacturing of metals, in: V. Schmidt, M.R. Belegratis (Eds.), 2013" Laser Technology in Biomimetics", Springer, Heidelberg, pp. p143e161.

13. Chow, S.P. 2000, "Artificial finger joints - its past, presentand future", Vol. 16 No. 2, pp. 83-5.

14. Christensen, A. 2004"Medical Modeling: Wohlers Report", pp. 195-206, ISBN 0-9754429-0-2. 